\title{
Application of Power Matrix Technique for Controlling DFIG Wind Turbine System
}

\author{
S. Jabeer Basha*, Loveswara Rao Burthi
}

Dept.of EEE, KL University, Vaddeswaram, Guntur, A.P, India

${ }^{*}$ Corresponding author, e-mail: t.krishnamohan02@gmail.com

\begin{abstract}
With advance in usage of wind turbine technologies, as compared with other renewable sources the cost of wind turbine becomes competitive. Due to these economic problems, other disadvantages and by considering the global warming, the utilization of wind turbine has increased since last decade. For maintain the active power at constant, the use of Doubly-Fed Induction Generators with Energy Storage System like super capacitor (or) batteries can be used, with a two layer control scheme. This paper presents a novel concept for controlling doubly fed induction generator called power transfer matrix. This power transfer matrix technique is designed based on the instantaneous values of active and reactive power of the system. In order to protect the DFIG during fault conditions a matrix converter scheme based power/current controller is presented.
\end{abstract}

Keywords: DFIG, wind turbine, power matrix converter

Copyright $\odot 2015$ Institute of Advanced Engineering and Science. All rights reserved.

\section{Introduction}

The electrical power generated by the wind system is one of the most reliable, efficient and developed renewable energy sources. The Doubly Fed Induction Generator is operated by a wind turbine with variable-speed variable-pitch control scheme. This system can be operated either grid connected mode or stand-alone mode. In present scenario the design of the wind turbine power plants is mainly depends on the DFIG technology. This DFIG-based windpower/storage system can deliver a specified amount of power to the grid, despite wind power fluctuations.

DFIG has two different control schemes stator flux reference frame used by for Rotor side control (RSC) is one and current reference frame used by Grid side control (GSC) is another to provide the firing pulses to the converters.

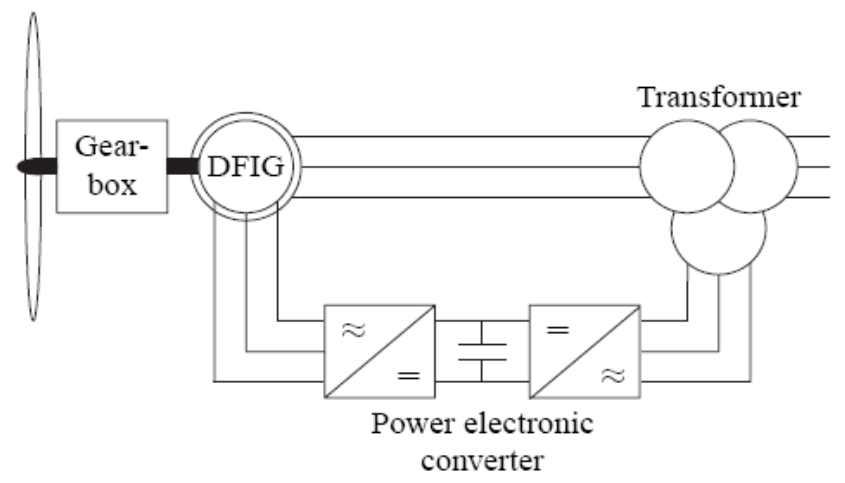

Figure 1. Schematic Diagram for DFIG based wind turbine

Figure 1 shows the schematic diagram for the wind turbine based doubly fed induction generator system. In this the stator is connected directly to the grid system and the rotor is controlled with the help of converters. 


\section{Modelling and Design of DFIG}

The doubly fed induction generator is the better solution for variable speed machines with tolerance $\pm 30 \%$ of synchronous speed. The grid and the rotor are directly connected for the main stator winding is controlled with converters via slip rings as shown in Figure 2.

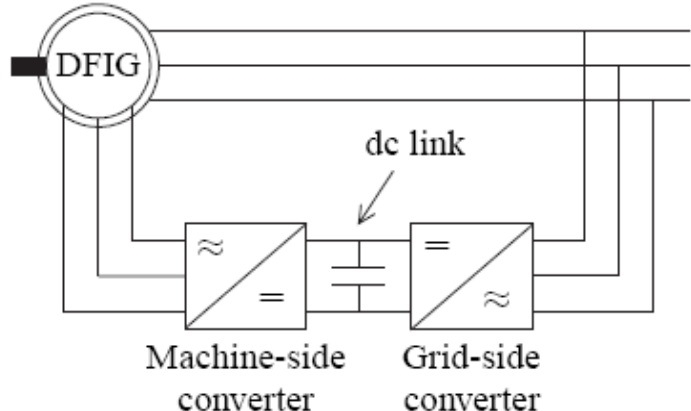

Figure 2. DFIG system with a Back to Back Converter

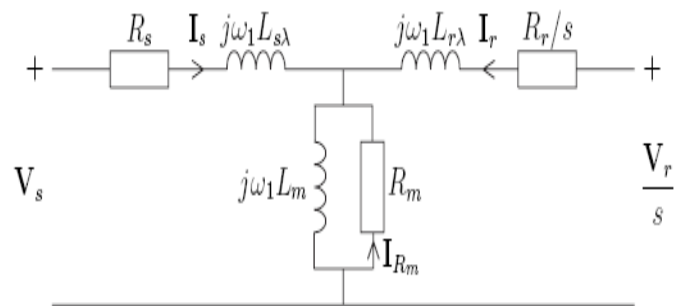

Figure 3. Equivalent circuit of DFIG

From application of Kirchhoff's voltage law applied to the above circuit 3, the voltage expressions for stator and rotor windings are expressed as:

$$
\begin{aligned}
& V s=j \omega_{1} L_{m}\left(I_{s}+I_{r}+I_{R m}\right)+j \omega_{1} L_{s \lambda} I_{s}+R_{s} I_{s} \\
& V_{r} / s=j \omega_{1} L_{m}\left(I_{s}+I_{r}+I_{R m}\right)+j \omega_{1} L_{r \lambda} I_{r}+R_{r} / s^{*} I_{r} \\
& 0=j \omega_{1} L_{m}\left(I_{s}+I_{r}+I_{R m}\right)+R_{m} I_{R m}
\end{aligned}
$$

Rotor flux, stator flux, air-gap fluxes used in Equation (1), (2) and (3) are defined below:

$$
\begin{aligned}
& \Psi_{m}=L_{m}\left(I_{s}+I_{r}+I_{R m}\right) \\
& \Psi_{s}=L_{s \lambda} I_{s}+\Psi_{m}=L_{s \lambda} I_{s}+L_{m}\left(I_{s}+I_{r}+I_{R m}\right) \\
& \Psi_{r}=L_{r \lambda} I_{r}+\Psi_{m}=L_{r \lambda} I_{r}+L_{m}\left(I_{s}+I_{r}+I_{R m}\right)
\end{aligned}
$$

The electro-mechanical torque is obtained from the above equations is expressed as:

$$
T_{e}=3 n_{p} l_{m} \Psi_{r} l_{r}^{*}=3 n_{p} I_{m} \Psi_{m} l_{r}{ }_{r}
$$

The rotor and stator powers are determined as:

$$
\begin{aligned}
& P_{s}=R_{e}\left[S_{s}\right]=3 R_{s}\left|I_{s}\right|^{2}+3 R_{m}\left|I_{R m}\right|^{2}+3 \omega_{1} I_{m}\left[\left.\Psi_{m}\right|^{*} r\right] \\
& \approx 3 \omega I_{m}\left[\Psi_{m} *_{r}^{*}\right] \\
& P_{r}=R_{e}\left[S_{r}\right]=\left.3 R_{r} I_{r}\right|^{2}-3 \omega_{1} s I_{m}\left[\left.\Psi_{m}\right|_{r} ^{*}\right] \\
& \approx-3 \omega_{1} s I_{m}\left[\left.\Psi_{m}\right|^{*} r\right.
\end{aligned}
$$

From these DFIG mechanical power equations are calculated by:

$$
P_{\text {mech }}=3 \omega_{r} I_{m}\left[\Psi_{m}{ }^{*}{ }_{r}^{*}\right]=3 \omega_{1} I_{m}\left[\Psi_{m} I_{r}^{*}\right]-3 \omega_{1} s I_{m}\left[\left.\Psi_{m}\right|^{*}{ }_{r}\right]
$$

\subsection{Wind-Turbine Based Doubly Fed Induction Generator}

With the help of induction generator conversion of electrical energy from generated mechanical power from the wind blades and by the stator it is connected to the grid and the 
rotor converter terminals. Rotor voltage command signal $\mathrm{Vr}$ and grid command signal $\mathrm{Vgc}$ and the pitch angle command are generated by the control techniques and the and respectively in order for controlling wind turbine power, the DC bus voltage between the rotor and stator converters and the voltage at the grid terminals.

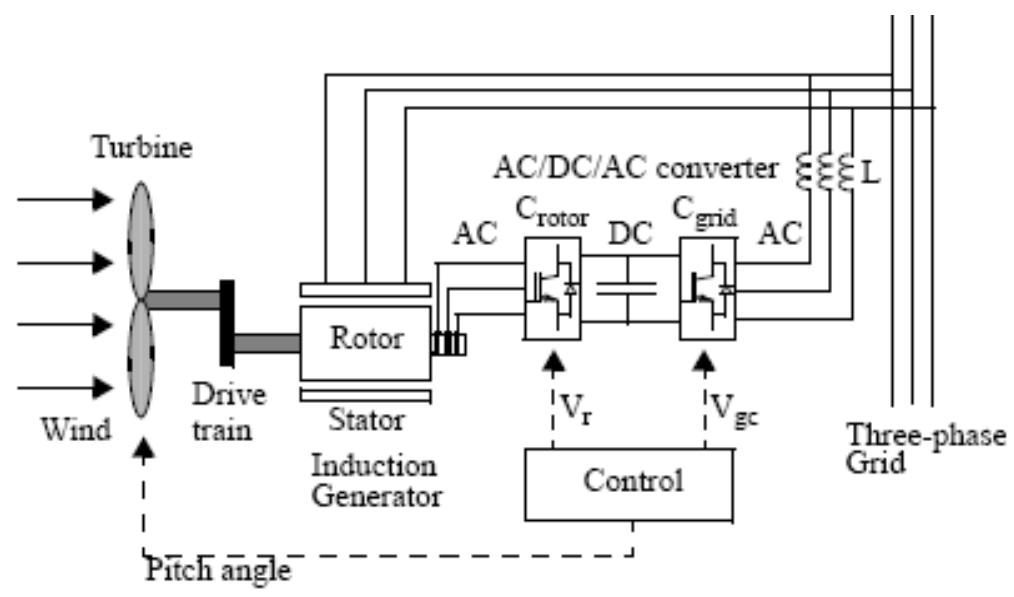

Figure 4. DFIG Connected to Wind Turbine

\subsection{Closed Loop Control Diagram for Rotor Side Controller}

In the RSC, the controller is used for controlling rotor power Ps and the power Qs in terms of controlling rotor regulation and rotating reference frame.

By considering the simplified equivalent circuit for stator winding as shown in Figure 3 and write the equations by using $\mathrm{KVL}$ as:

$$
\begin{aligned}
& \bar{V}_{r}=\bar{I}_{r} R_{r}+\frac{d \psi_{r}}{d t} \\
& \bar{\psi}_{r}=L_{r} \bar{I}_{r}+M \bar{I}_{s} e^{-j \epsilon}
\end{aligned}
$$

Substituting the value of $\bar{\psi}_{r}$ in above equation e get:

$$
\begin{aligned}
& \bar{V}_{r}=\bar{I}_{r} R_{r}+\frac{d}{d t}\left(L_{r} \bar{I}_{r}+\frac{M}{L_{s}} \bar{\psi}_{s} e^{-j \in}-\frac{M^{2}}{L_{s}} \bar{I}_{r}\right. \\
& =\bar{I}_{r} R_{r}+\frac{d}{d t}\left(L_{r} \bar{I}_{r}-\frac{M^{2}}{L_{s}} \bar{I}_{r}\right)+\frac{d}{d t}\left(\frac{M}{L_{s}} \psi_{s} e^{-j \epsilon}\right)
\end{aligned}
$$

Figure 5 shows the overall RSC control scheme which is having two cascade loops. The active and reactive powers of the DFIG is controlled by the outer loop and direct axis current component $\mathrm{Idr}^{*}$, quadrature axis current component $\mathrm{Iqr}^{*}$ are generated. Inner-loop current regulation is the second cascaded control loop. Vdr0 and Vqr0 are the from the two regulated current controllers outputs. And these signals are used for generating Pulses to RSC converter by PWM technique. 


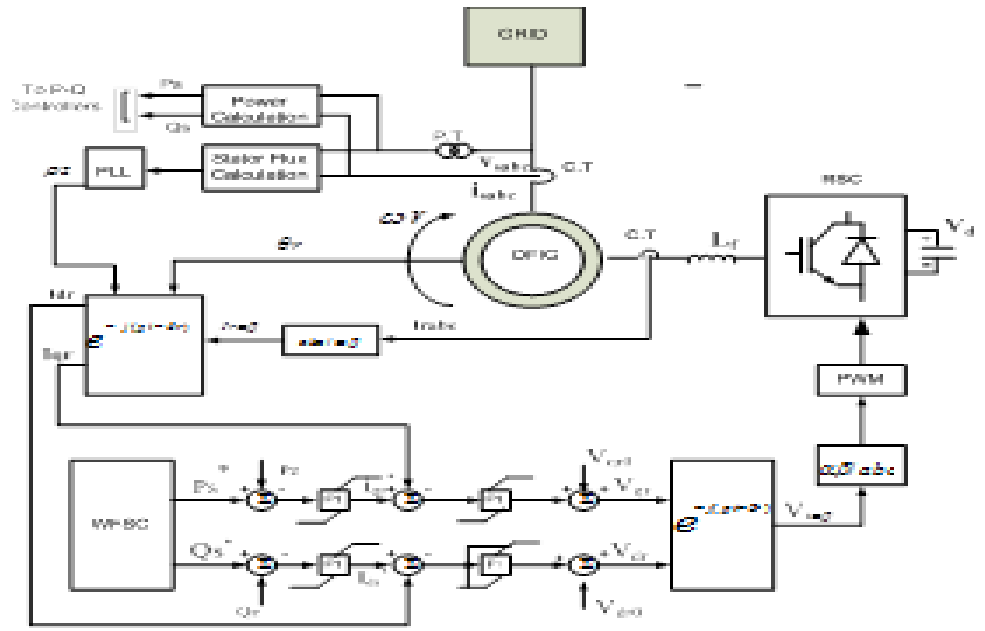

Figure 5. Control Diagram for the rotor side controller

\subsection{Closed Loop Control Diagram Grid Side Converter}

Controlling of the reactive power $\mathrm{Qg}$ which is exchanged between the stator side converter and the grid with the help of dc link voltage is the complete control scheme for the GSC.

Form the equivalent circuit shown in Figure 3. Applying KVL to above circuit we get:

$$
\begin{aligned}
& v_{a}=I_{a} R_{f}+L_{f} \frac{d I_{a}}{d t}+v_{a g} \\
& v_{b}=I_{b} R_{f}+L_{f} \frac{d I_{b}}{d t}+v_{b g} \\
& v_{c}=I_{c} R_{f}+L_{f} \frac{d I_{c}}{d t}+v_{c g}
\end{aligned}
$$

Transform the above three phase coordinates in to two phase $d$-q transformation and separate real \& imaginary terms we get:

$$
v_{s d}=I_{s d} R_{f}+L_{f} \frac{d I_{s d}}{d t}-w_{s} L_{f} I_{s q}+v_{g} v_{s q}=I_{s q} R_{f}+L_{f} \frac{d I_{s q}}{d t}-w_{s} L_{f} I_{s d}
$$

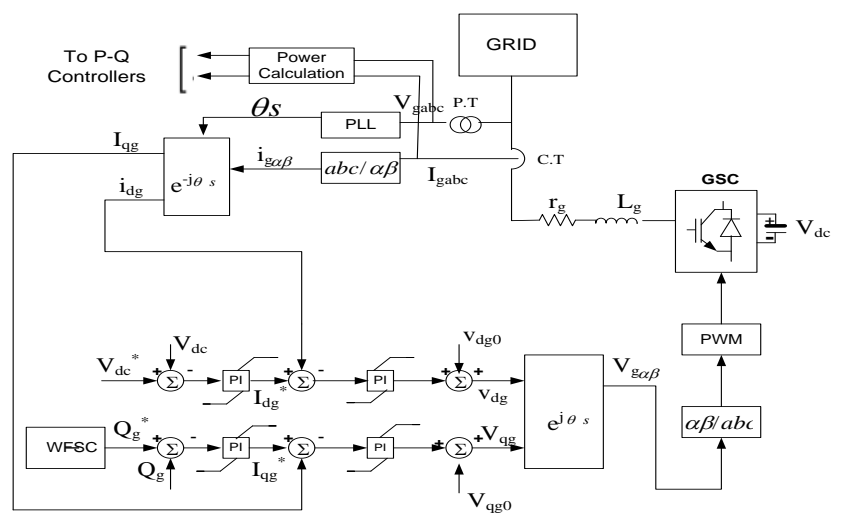


Figure 6. Grid side controller (GSC) scheme

Figure 6 shows the complete closed loop control diagram for the grid side converter and it having two cascaded control loops. The reactive power is indirectly controlled by the dc link voltage controlling done by the outer control loop for generating the reference signals of the $d$ axis current component idg* and $q$-axis current component iqg* for the inner-loop current regulation. Then these signals are used for generating pulses with the help of PWM technique.

$$
P_{e i, \max }=P_{m i, \max }-P_{L i}=P_{s i, \max }+P_{r i, \max }
$$

The stator active power Ps can be written as:

$$
P_{s}=\frac{3}{2}\left(v_{d s} i_{d s}+v_{q s} i_{q s}\right)=\frac{3}{2}\left[\omega_{s} L_{m}\left(i_{q s} i_{d r}-i_{d s} i_{q r}\right)+r_{s}\left(i_{d s}^{2}+i_{q s}^{2}\right)\right]
$$

The rotor side active power can be expressed:

$$
P_{r}=\frac{3}{2}\left(v_{d r} i_{d r}+v_{q r} i_{q r}\right)=\frac{3}{2}\left[-s \omega_{s} L_{m}\left(i_{q s} i_{d r}-i_{d s} i_{q r}\right)+r_{r}\left(i_{d r}^{2}+i_{q r}^{2}\right)\right]
$$

\section{Simulation Diagram and Results}

Here the simulation is done for maintaining the real power supplied by the wind farm is to be maintained constant. The constant real power is given as Pref to the wind turbines under different conditions like wind turbines operating without any energy storage system, operating with energy storage system with two layer conventional controllers. The amount of real power that has to be maintained constant. The simulation diagram is shown in Figure7.

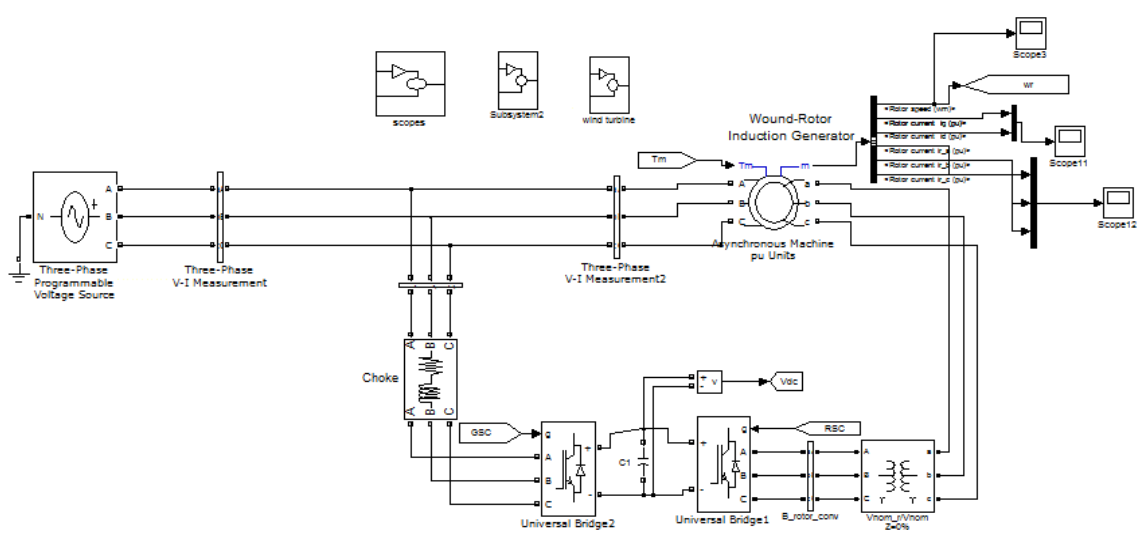

Figure 7. Simulation Diagram for DFIG WIND turbine

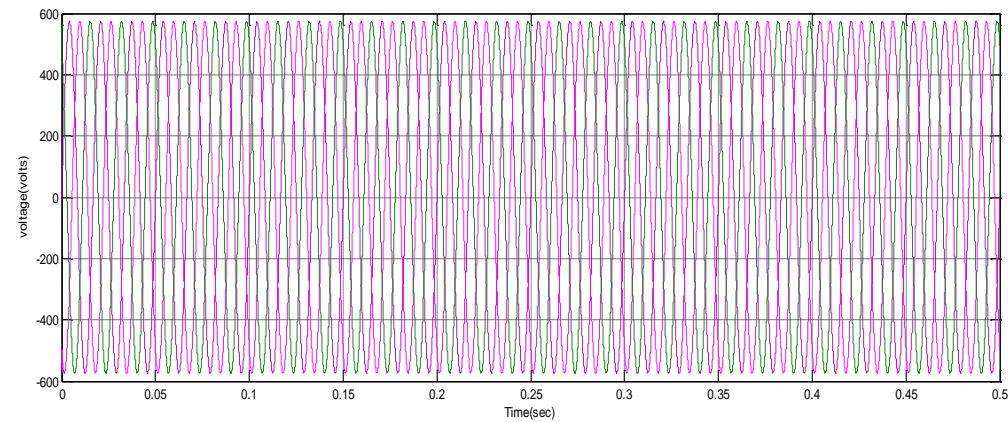


Figure 8. DFIG Stator Voltage

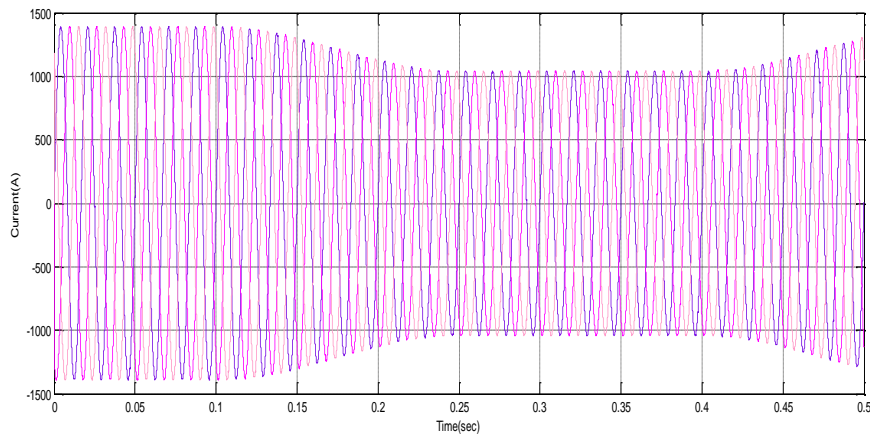

Figure 9. DFIG Stator Current

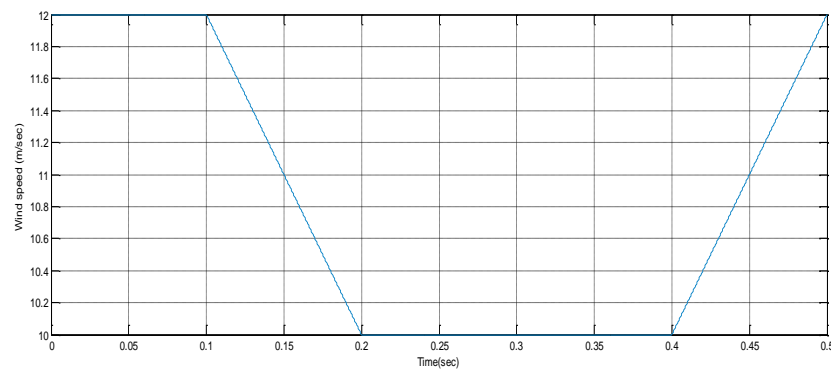

Figure 10. Wind turbine Speed

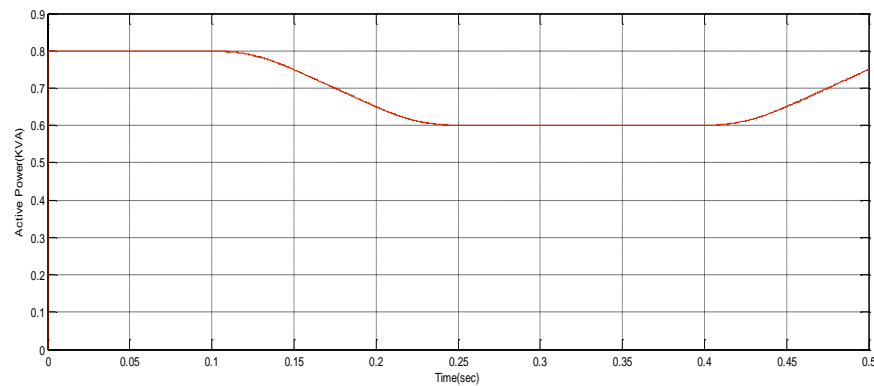

Figure 11. Active power at grid side

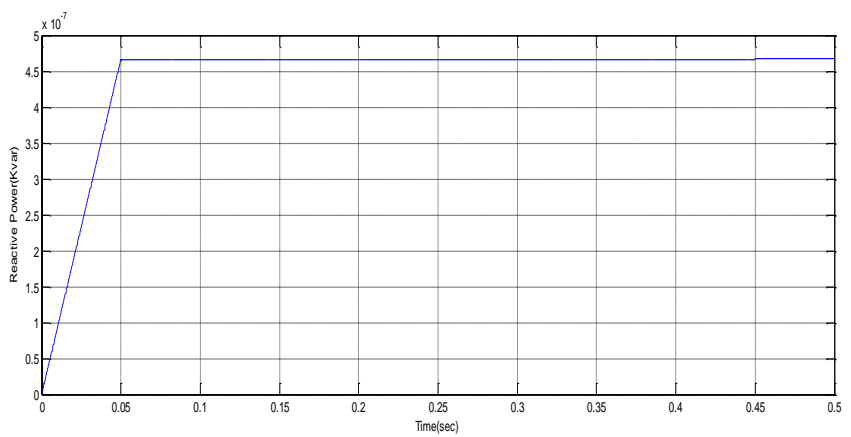

Figure 12. Grid Reactive Power

\section{Conclusion}

This paper proposed a concept of power matrix technique for controlling the doubly-fed induction generator based wind turbine energy generation units. These power components have

TELKOMNIKA Vol. 16, No. 2, November 2015: $265-271$ 
different reference frame quantitative and can be obtained with the help of voltage and currents. Therefore, this controller improves the performance and robustness of the DFIG system. This proposed approach is verified through time based analysis of a DFIG based wind energy systems. Then the simulation results show that the proposed control diagram of a power matrix technique has succefully control the rotor speed for obtaining the constant value of dc link voltage and control of powers with their reference values.

\section{References}

[1] T Ackermann, et al. Wind Power in Power System. John Wiley \& Sons. 2005.

[2] W Qiao, RG Harley. Grid connection requirements and solutions for DFIG wind turbines. In Proc. IEEE Energy 2030 Conference. Atlanta, GA, USA. 2008.

[3] C Abbey, G Joos. Super capacitor energy storage for wind energy applications. IEEE Trans. Industry Applications. 2007; 43(3): 769-776.

[4] C Abbey, G Joos. Integration of energy storage with a doubly-fed z.1, induction machine for wind power applications. Proceedings of IEEE Power Electronics Specialists Conference, PESC 04. 2004; 3: 1964-1968.

[5] R Pena, JC Clare, GM Asher. Doubly fed induction generator using back-to-back PWM converters and its application to variable speed wind-energy generation. Proc. Inst. Elect. Eng. 1996; 143(3): 231-241.

[6] W Leonhard. Control of Electrical Drives. 3rd ed. Springer. 2001.

[7] A Petersson, L Harnefors, T Thiringer. Evaluation of current control methods for wind turbines using doubly-fed induction machines. IEEE Trans. Power Electron. 2005; 20(1): 227-235.

[8] A Petersson. Analysis, Modelling, and Control of Doubly-Fed Induction Generators for Wind Turbines. Ph.D. dissertation. Goteborg, Sweden: Chalmers Univ. Technol; 2005. 